\title{
Emulation of Energy Scheduling for an Agriculture Irrigation System Considering Field Data
}

\author{
Omid Abrishambaf, Pedro Faria, Zita Vale \\ Polytechnic of Porto (IPP), Porto, Portugal \\ ombaf@isep.ipp.pt, pnf@isep.ipp.pt, zav@isep.ipp.pt
}

\begin{abstract}
As the global population is daily soaring, the need for water and energy is also increasing. This makes the role of the agriculture sector more tangible. Water and energy efficiency in this sector is still very low, and the need for smart management and strategic planning are obvious. This paper proposes an autonomous approach to increase the efficiency of energy and water consumption in the agriculture irrigation process. The model contains local renewable energy resources to supply the irrigation electricity demand. In the previous works developed by the authors, the irrigation scheduling had been performed by a decision tree approach. however, in this paper, the model schedules irrigation according to the real-time field data as well as the availability of the local resources to minimize operational costs. The system also includes a laboratory demonstration to test the scheduling process under practical challenges. A case study is also shown to validate the model, and its results show a gap between expected and real results. Nevertheless, the results proved the functionality and applicability of the proposed model.
\end{abstract}

Keywords-Agriculture, Energy scheduling, Automation, $P L C$, Synchronous generator.

\section{INTRODUCTION}

The world population is increasing day by day and it is estimated to have 10 billion by 2050 [1]. Therefore, by the soaring global population, the need for food and water and energy are being increased as well [2]. This makes the role of the agriculture sector more important than before. Currently, in the traditional agriculture systems, the water, and energy efficiency are at a very low rate, and this makes the farmers more worry than before since an affordable agriculture process is their main point [3].

In terms of water usage, the purpose of irrigation is to provide an adequate amount of water to the plants to guarantee their necessities. For this purpose, soil water in the desired zone must be maintained in a range between the upper and lower limits for the plants [4]. Appropriate irrigation management increases the efficiency of water usage, considering time and amount of irrigation [5].

There are several irrigation methods in the agriculture sector. The main intention of all is to have minimum operation costs for reaching the maximum yield of the crop. One of the methods that increase the efficiency of water and energy usage, is sprinkler with a system of the Center Pivot (CP) [6]. In this approach, the equipment rotates in a circular path around a pivot, and the crops are irrigated with sprinklers. Moreover, multi-depth sensors can be used for monitoring the soil conditions to improve the efficiency of the irrigation duration [7].

The present work was done and funded in the scope of the following project: Eco Rural IoT project funded by TETRAMAX-VALUECHAINTTX-1, CEECIND/02887/2017 and UIDB/00760/2020 funded by FEDER Funds through COMPETE program and by National Funds through FCT.
Nowadays, the agriculture sector is one of the largest emitters of Greenhouse Gases (GHG). The U.S. emission inventory states that methane is the main GHG that is produced in agriculture tactical operations. In the same statement, it is shown that between $14 \%$ to $30 \%$ of these GHG emissions are related to the fossil fuels that have been used in this sector for the pump water and irrigation purposes. This shows the need for exchanging fossil fuels to Renewable Energy Resources (RERs) in the agriculture sector [8].

Another vision of using RERs is to reduce the energy costs for agriculture tactical services [9]. The agriculture sector can benefit from natural sources, such as rivers, wind, and solar to produce electricity [10], since they are mostly located in natural areas. However, before the implementation of any model, theoretical and practical validation phases are required to reveal the problems.

This paper describes an autonomous methodology for an optimal and efficient agriculture irrigation system. The model contains several sensors to monitor the real-time soil and crop conditions, so an optimal irrigation period can be selected to maintain the needs of the crops. The proposed model also includes local renewable and sustainable energy resources, so several decision rules have been implemented in a controller to perform energy scheduling to supply energy demand from the local resources. While the optimal irrigation period has been calculated, a laboratory emulation experiment is performed to examine and validate the proposed model under technical and practical challenges.

Several similar research works have been developed in this context. A CP irrigation model has been presented in [6], which uses a wireless underground sensor network to monitor the soil condition in real-time. In [8], the authors developed an offline energy scheduling methodology for the agriculture systems using RERs considering the decision tree method. In the same work, a set of laboratory emulators have been employed to validate the performance of the decision tree approach. However, the authors in [8] did not take into account any field data in the irrigation scheduling process. In [11], the authors demonstrated an autonomous method to optimize the use of water and energy consumption in a crop management system. In the same work, the field data have been used in the optimization process, and the method only was validated through a numerical case study. In [12], a decision tree approach was proposed for energy scheduling in an agriculture irrigation system. In the same work, the authors had a specific survey on the performance of the decision tree itself. In [13], the authors proposed a local agriculture microgrid with RERs and water storage units, in which energy consumption has been optimized by interacting with electricity markets.

The main contribution of this paper is to provide an autonomous irrigation scheduling considering field data, and 
local energy resources in order to minimize electricity costs and water consumption. Also, the novelty of this work is to show and compare the numerical and experimental irrigation scheduling results through a laboratory testbed developed for validating energy scheduling methods.

After this section, the developed methodology is shown in Section II. Laboratory demonstration and employed equipment are described in Section III. A case study including two scenarios is shown in Section IV to test the model, the adapted results are shown in Section V. Finally, section VI shows the conclusions of the work.

\section{METHODOLOGY}

This section, at first, presents the considered Center Pivot (CP) irrigation system in the agriculture field as well as the energy resources proposed to supply the electricity demand for irrigation equipment. Then, a set formulation is described to estimate the period and the adequate amount to irrigate the crops based on field data.

\section{A. CP Irrigation System}

In fact, in the agriculture systems, the main purpose is to read the maximum yield of the crops considering the minimum operational costs and water usage. The method considered in this paper is according to the CP irrigation system to increase the efficiency level of water and electricity consumption.

The presented irrigation method considers multiple zones of the agriculture field enabling the user to have various plantations or planting the same sort but different levels of growth. Fig. 1 illustrates the $\mathrm{CP}$ irrigation system considering multiple zones.

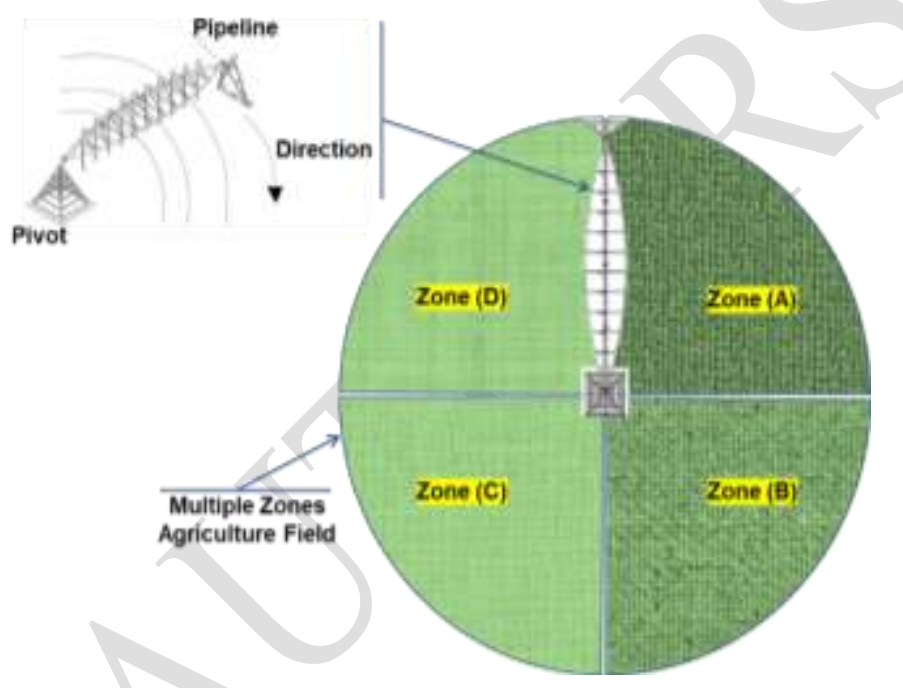

Fig. 1. Multiple zones CP irrigation system.

As Fig. 1 shows, the CP system rotates around a pivot, in a circular path to irrigate the crops with sprinklers as the machine moves. Also, the system takes into account the requirements of the crops in each zone in order to adjust the speed of the electrical motor related to the rotation of the irrigation infrastructures, and also the valve motor related to the water pump to regulate the intensity of the irrigation for the crops in a specific zone.

Regarding the energy resources of the proposed agriculture system, two renewable and sustainable energy resources are considered. The main intention of the system is to supply electricity demand from local energy resources. Fig. 2 shows the energy resources considered in the model. The system relies on Photovoltaic (PV) Panels, a synchronous generator, and utility grid, as energy sources. Also, it is considered that the agriculture field is located next to a river, where a turbine is placed on the river that rotates the shaft of the synchronous generator. Moreover, the electric motors shown in Fig. 2 are related to the rotation and valve motors of the CP irrigation infrastructure.

The main controller of this system is a Programmable Logic Controller (PLC) responsible for managing all the consumption and generation resources. The PLC manages the system based on two layers: (i) Monitoring layer, including several energy meters connected to the PLC, one for each resource to monitor the real-time consumption and generation of the system. (ii) Controlling layer, to adjust the plunging level of river turbine to regulate the speed of the synchronous generator's shaft; And also controlling the speed of electric motors for managing the rotation's speed of CP equipment as well as regulating the intensity of the irrigation.

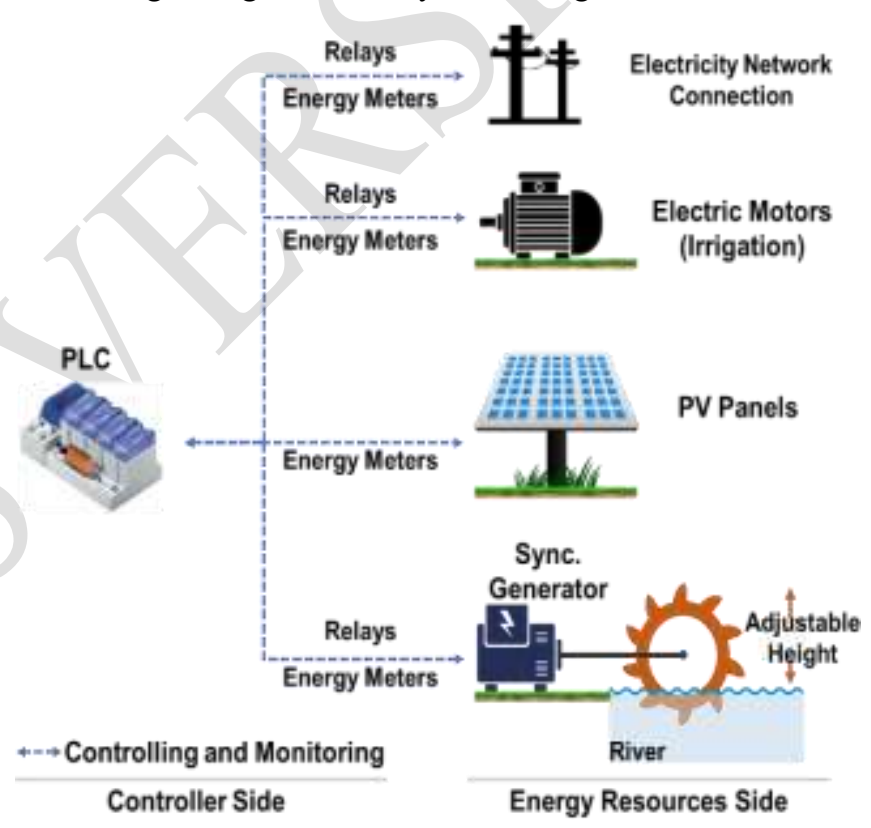

Fig. 2. Energy resources considered in the agriculture system.

In fact, while the river turbine is plunged in the deeper height of the river, the rotation speed of the synchronous generator is increased, and therefore, the generation rate will be soared. Thus, the PLC can regulate the output power production of the synchronous generator, by controlling the plunge height of the river turbine.

Also, there are several sensors in the proposed agriculture model enabling the energy scheduling process to have realtime information regarding soil moisture, solar radiation, temperature, humidity, etc. Furthermore, the system calculates the remaining time until the level of soil moisture goes below a favorable limit for the plantations of the different zones by taking into account the evapotranspiration of each zone and the precipitation forecast.

\section{B. Decision Rules Calculations}

As it was mentioned, the main goal of this system is to supply the electricity demand from the local energy resources (PV and synchronous generator). Therefore, it is necessary to have decision rules in the PLC to perform the optimal 
operation according to the real-time data. The decision rules that control the system are shown in Fig. 3, which has been implemented in the PLC based on "if-then" method.

For this purpose, several decision rules have been implemented in the PLC, so the system can operate in an optimal approach without the need of the communicating with a server and external entities because all the decision making is performed locally in the PLC.

As Fig. 3 shows, the first rule defined in the PLC is to supply the consumption from the local PV production since the produced energy by PV panels is not controllable in this model. If PV is not sufficient for the demand, the PLC connects the synchronous generation to the circuit and controls its output by regulating the plunge height of the river turbine. In the final stage, if both $\mathrm{PV}$ and synchronous generators are not enough for the demand, the rest of consumption is being supplied by the electricity network.

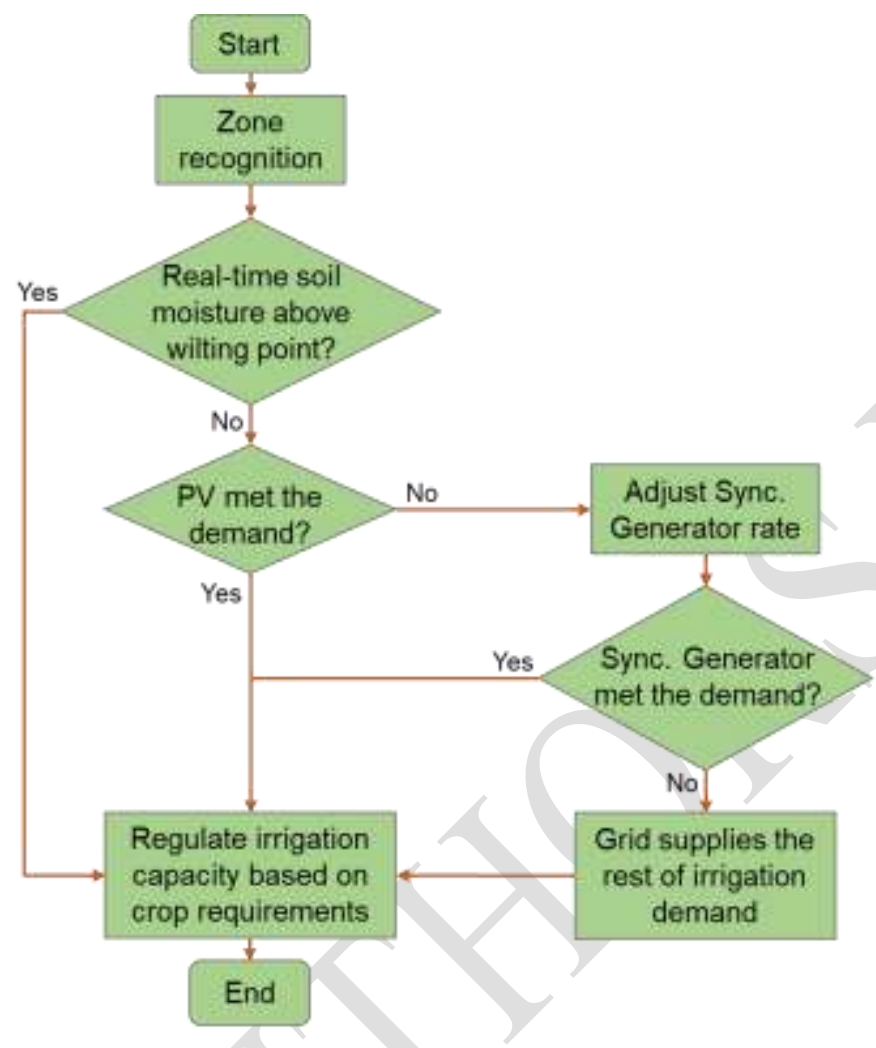

Fig. 3. Flowchart of energy scheduling for irrigation energy consumption.

To estimate the period and the adequate amount to irrigate the field, it is necessary to calculate the evapotranspiration of the plantations. For this purpose, the Penman-Monteith method [14] introduced by Food and Agriculture Organization (FAO - www.foa.org) has been adapted to calculate the potential evapotranspiration (ET0) and the evapotranspiration of the crop (ETc).

Equation (1) shows the calculation of the potential evapotranspiration considering the stage of vegetative growth of the crop by weighting the potential evapotranspiration $(\mathrm{Kc})$.

$$
E T_{0}=\frac{0.408 \Delta\left(R_{n}-G\right)+\gamma \frac{900}{T+273} U_{2}\left(e_{s}-e_{a}\right)}{\Delta+\gamma\left(1+0.34 U_{2}\right)}
$$

$\mathrm{ET}_{0} \quad$ Reference evapotranspiration $\left[\mathrm{mm} \cdot \mathrm{day}^{-1}\right]$;

$\mathrm{R}_{\mathrm{n}} \quad$ Net radiation at the crop surface $\left[\mathrm{MJ} \cdot \mathrm{m}^{-2}\right.$. day $^{-1}$;

G Soil heat flux density $\left[\mathrm{MJ} . \mathrm{m}^{-2}\right.$.day $\left.{ }^{-1}\right]$;

$\mathrm{T} \quad$ Air temperature at $2 \mathrm{~m}$ height $\left[{ }^{\circ} \mathrm{C}\right]$;

$\mathrm{U}_{2} \quad$ Wind speed at $2 \mathrm{~m}$ height $\left[\mathrm{m} \cdot \mathrm{s}^{-1}\right]$;

$\mathrm{e}_{\mathrm{s}} \quad$ Actual vapour pressure $[\mathrm{kPa}]$;

$\mathrm{e}_{\mathrm{a}} \quad$ Actual vapour pressure $[\mathrm{kPa}]$;

$\mathrm{e}_{\mathrm{s}}-\mathrm{e}_{\mathrm{a}} \quad$ Saturation vapour pressure deficit $[\mathrm{kPa}]$

$\Delta \quad$ Slope vapour pressure curve $\left[\mathrm{kPa}^{\circ} \mathrm{C}^{-1}\right]$;

$\gamma \quad$ Psychrometric constant $\left[\mathrm{kPa}^{\circ} \mathrm{C}^{-1}\right]$.

To calculate the evapotranspiration of the crop (ETc), (2) is presented, which is calculated based on ET0 and $\mathrm{KC}(\mathrm{KC}$ is a coefficient determined based on the type and growth length of the crop).

$$
E T_{c}=E T_{0} \times K_{c}
$$

In sum, this section showed the theoretical concepts of the proposed methodology regarding the CP irrigation system. The related energy resources and the decision rules regarding energy scheduling and optimal irrigation periods were also demonstrated. In the next section, the set of laboratory equipment is demonstrated to implement the proposed model using real infrastructures.

\section{LABORATORY DEMONSTRATION}

This section shows the laboratory equipment (emulators) used for modeling the energy scheduling of the agriculture model. All emulators are managed by a PLC, which is considered as the core of the developed agriculture model. Fig. 4 demonstrates two emulators used in this model. The synchronous generation emulator (so-called Syn. Gen. Emulator in this paper) includes a $2.5 \mathrm{~kW}$ synchronous generator coupled with a three-phase induction motor. The induction motor models the river turbine described in Section II-A for rotating synchronous generator's shaft.

In other words, controlling the speed of induction motor in Syn. Gen. Emulator is an equivalent process as adjusting the plunging level of the river turbine to control the production of the synchronous generator. More information about how the PLC controls this emulator is available on [8], which has been developed by the authors in the scope of their previous works.

The second emulator used in this model is a group of threephase induction motors (so-called Motor Bench in this paper), as Fig. 4 shows. This bench consists of two $1.5 \mathrm{~kW}$ motor with a constant load, and one $2.5 \mathrm{~kW}$ motor connected to an electric brake system to have a variable rate of the load.

In this model, the two motors with constant loads are considered for the valve motors related to the water pump, and the $2.5 \mathrm{~kW}$ motor with variable load is considered for the rotation of the irrigation infrastructures.

In addition to these emulators, a real installation of $7.5 \mathrm{~kW}$ rooftop PV arrays is considered for the proposed agriculture model. This installation is in a research center in Porto, Portugal, and it is connected to the same electrical network as the emulators are connected. In this way, all the components of the system are electrically linked together to create a local microgrid connected to the main electrical network.

Where: 


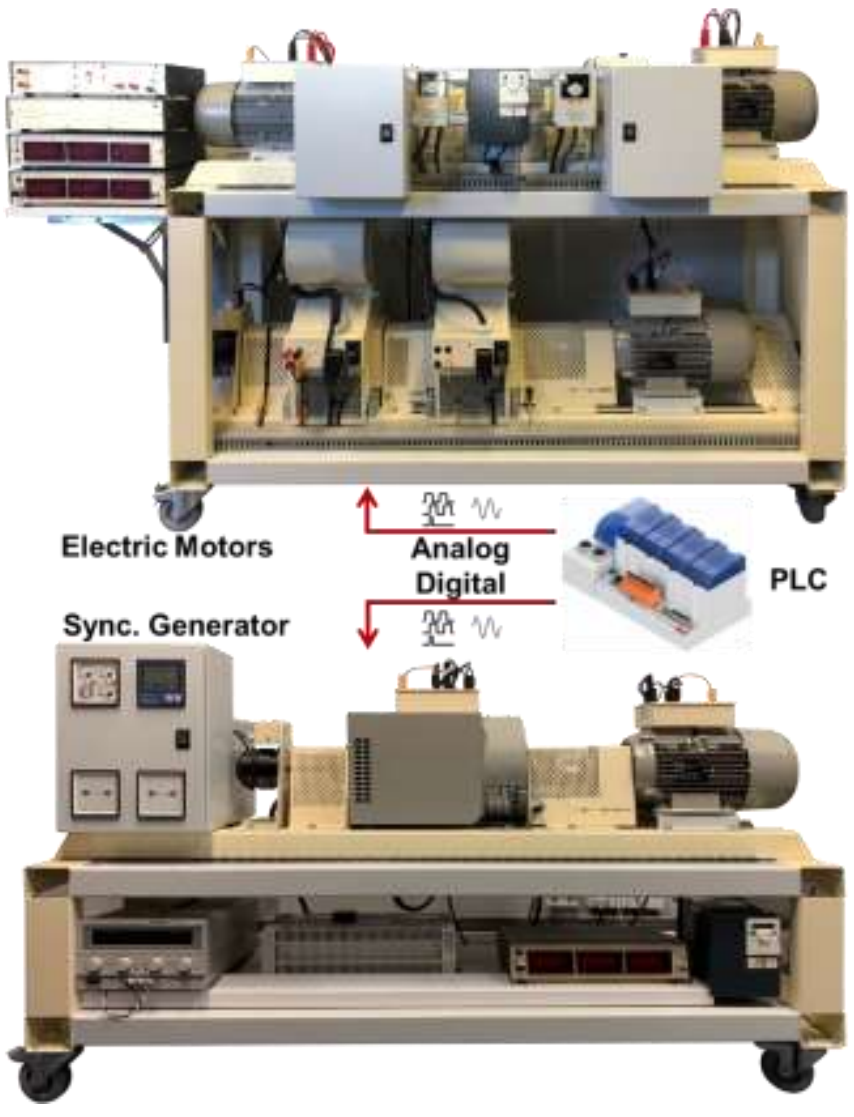

Fig. 4. Laboratory emulators for energy scheduling of agriculture model.

\section{CASE STUDY}

This part demonstrates a case study including two scenarios to validate and examine the performance of the system. For this purpose, a real production profile adapted from the research center database is provided considered for the system as Fig. 5 - (A) shows. Also, electricity market prices considered for the scenarios are shown in Fig. 5 - (B), which have been adapted from the Iberian Electricity Market (www.omie.es). All data shown in this section are considered as day-ahead data, for 24 periods of 1 hour ( 24 hours in total).
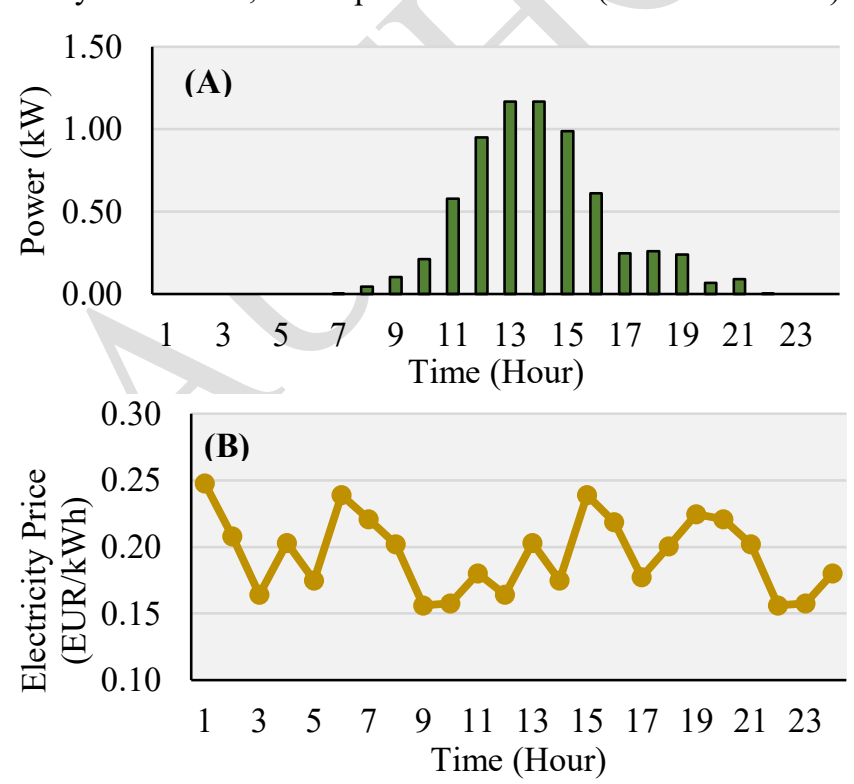

Fig. 5. Input data for the proposed agriculture system: (A) PV production profile; (B) Electricity prices.
The profiles shown in Fig. 5 are equal for both scenarios, and only the critical parameters regarding the field data are changed to examine the system.

Table 1 shows the parameters considered for the two proposed scenarios. The system will calculate the most economical and optimal period for irrigation based on the data shown in Fig. 5 and Table 1. The input values shown in Table 1 are only some assumptions for this specific agriculture system, and they can be different in other models based on the application.

TABLE I. INPUT PARAMETERS FOR TWO PROPOSED SCENARIOS.

\begin{tabular}{l|c|c}
\hline \hline Parameters & Scenario 1 & Scenario 2 \\
\hline \hline Initial soil moisture level $[\mathrm{mm}]$ & 1000 & 1600 \\
\hline Evapotranspiration crop $[\mathrm{mm}]$ & 35 & 50 \\
\hline Wilting point plantation $[\mathrm{mm}]$ & 750 & 1000 \\
\hline Irrigation capacity $[\mathrm{mm} / \mathrm{min}]$ & 35 & 85 \\
\hline Desired soil moisture level $[\mathrm{mm}]$ & 1700 & 2500 \\
\hline Precipitation Forecast $[\mathrm{mm}]$ & 30 & - \\
\hline \hline
\end{tabular}

The precipitation forecast considered in scenario 1 happens only in four periods (between 05:00 AM to 08:00 AM) with 30 millimeters in each period. In this way, the soil moisture is increased during these periods, and irrigation will be performed for a shorter period in order to reach the desired soil moisture level. In the next section, the results of these two scenarios are shown, and the system is run for a short period to survey the technical features.

\section{RESUlTS}

In this part, at first, the results of the optimal irrigation periods for both scenarios are shown, and then, the focus is given to the most optimal period in one of the scenarios to perform laboratory emulation tests. The results of optimal irrigation periods are demonstrated in Table 2. Table 2 shows the irrigation scheduling with its cost in each period. In the same table, green is the most economical period for irrigation and red is the most expensive period.

TABLE II. THE RESULTS OF IRRIGATION SCHEDULING CALCULATIONS

\begin{tabular}{c|c|c|c||c|c|c}
\hline \hline \multirow{2}{*}{ Period } & \multicolumn{3}{|c||}{ Scenario 1 } & \multicolumn{3}{c}{ Scenario 2 } \\
\cline { 2 - 7 } & $\begin{array}{c}\text { Soil moisture } \\
{[\mathrm{mm}]}\end{array}$ & $\begin{array}{c}\text { Duration } \\
{[\mathrm{min}]}\end{array}$ & $\begin{array}{c}\text { Cost } \\
{[\text { EUR] }}\end{array}$ & $\begin{array}{c}\text { Soil moisture } \\
{[\mathrm{mm}]}\end{array}$ & $\begin{array}{c}\text { Duration } \\
{[\mathrm{min}]}\end{array}$ & $\begin{array}{c}\text { Cost } \\
{[\mathrm{EUR}]}\end{array}$ \\
\hline \hline 1 & 1000 & 20 & 1.651 & 1600 & 11 & 2.185 \\
\hline 2 & 965 & 21 & 1.456 & 1550 & 11 & 2.328 \\
\hline 3 & 930 & 22 & 1.203 & 1500 & 12 & 2.039 \\
\hline 4 & 895 & 23 & 1.557 & 1450 & 12 & 2.090 \\
\hline 5 & 890 & 23 & 1.348 & 1400 & 13 & 2.049 \\
\hline 6 & 885 & 23 & 1.854 & 1350 & 14 & 2.694 \\
\hline 7 & 880 & 23 & 1.723 & 1300 & 14 & 2.596 \\
\hline 8 & 875 & 24 & 1.589 & 1250 & 15 & 2.478 \\
\hline 9 & 840 & 25 & 1.279 & 1200 & 15 & 1.990 \\
\hline 10 & 805 & 26 & 1.344 & 1150 & 16 & 2.087 \\
\hline 11 & 770 & 27 & 1.597 & 1100 & 16 & 2.474 \\
\hline 12 & - & - & - & 1050 & 17 & 2.332 \\
\hline \hline
\end{tabular}

The duration of irrigation shown in Table 2 is by respect to the real-time and desired soil moisture level as well as the irrigation capacity. Also, in Table 2, the irrigation schedule is 
shown until one period before the soil moisture goes below the wilting point. If the soil moisture becomes equal to the wilting point, the irrigation process should be performed in any condition, and therefore, no decision rules are required for scheduling.

Furthermore, since there is a precipitation forecast in the period $\# 5$ to \#8, the decline rate in soil moisture level becomes slowly comparing with other periods.

As it can be seen in Table 2, the most economic period for irrigation is period $\# 3$ in scenario 1 , and period $\# 9$ in scenario 2. Considering these results, the focus now is given to the most optimal period in scenario 2 (period \#9 with 15 minutes irrigation duration) to perform the emulation test. The energy scheduling results during this optimal period are demonstrated in Fig. 6.

As Fig. 6 shows, the PV is the first energy resource to supply, and then, if its energy is not sufficient to supply the demand, the synchronous generator is being employed. Also, there are some periods that local energy resources are not enough for the requested demand, therefore, the system relies on the utility grid to supply the consumption.

Regarding the emulation results, Fig. 7 shows the real results adapted from the laboratory emulators. The experimental generation profile adapted from the Syn. Gen. Emulator is shown in Fig. 7 - (A), and consumption profile emulated by the Motor Bench is illustrated in Fig. 7 - (B). In fact, the set points in Fig. 7 - (A) is as same as blue areas in Fig. 6, and in Fig. $7-(\mathrm{B})$ is equal to the total consumption shown in Fig. 6.

In Fig. 7, each period presents 0.05 seconds (PLC time step), which in total there are 1800 periods for 15 minutes. The instabilities of the emulated profiles in Fig. 7 is due to the technical features, such as electrical grid conditions including voltage and frequency variations.

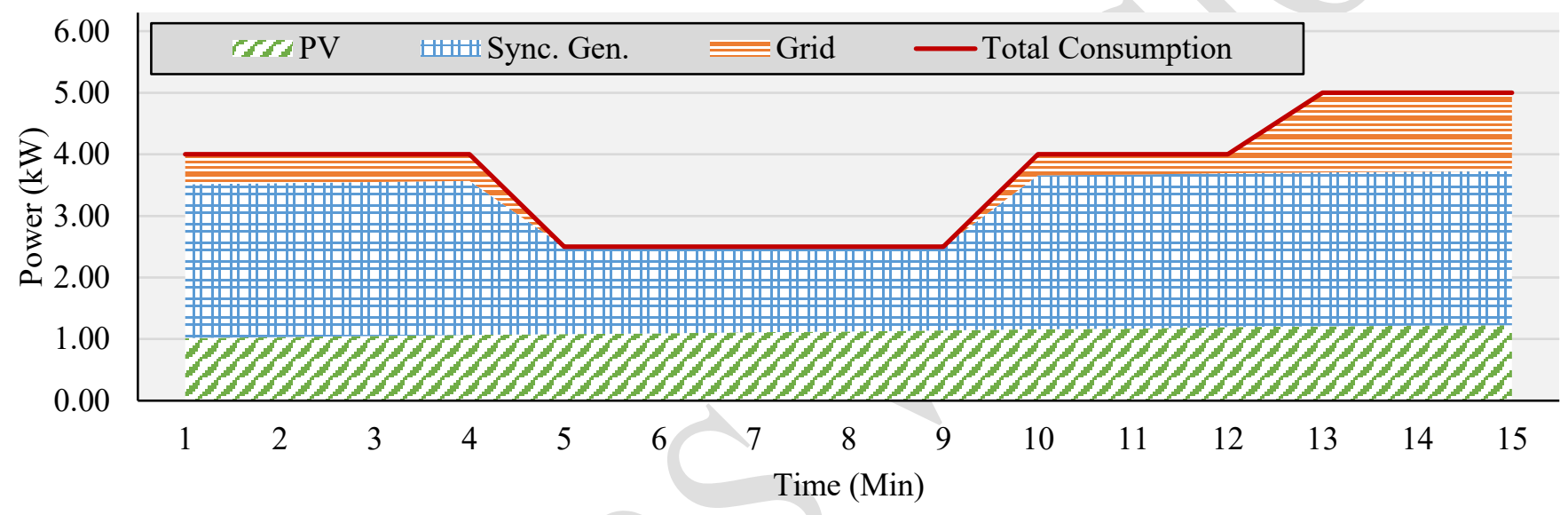

Fig. 6. Energy scheduling results for 15 minutes.
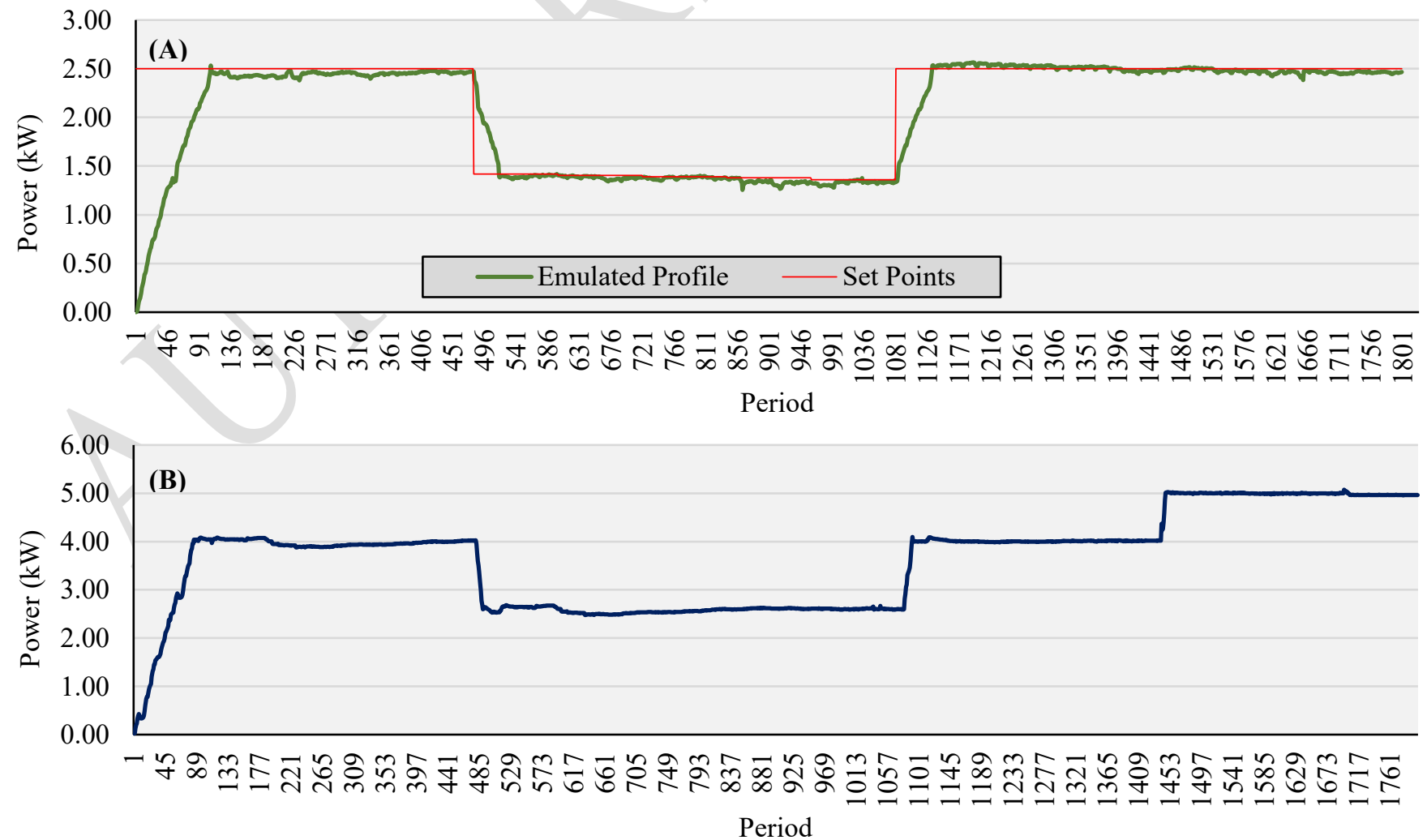

Fig. 7. Actual results adapted from laboratory emulators: (A) Generation profile of Syn. Gen. Emulator; (B) Consumption profile of Motor Bench. 


\section{CONCLUSIONS}

This paper proposed an autonomous methodology for an optimal and efficient agriculture irrigation system. The method used several real-time field data to fulfill the needs of crops. Furthermore, several decision rules enable the model to perform energy scheduling and supply the energy demand from the local renewable energy resources, and by considering electricity market prices.

Two scenarios were assumed for testing the irrigation scheduling process, and the results proved that such an approach enables the farmers to have affordable irrigation and smart management to reduce irrigation costs. Also, an emulation test was performed to test the model under technical and practical challenges.

The results demonstrated a gap between the expected and real results. This is the main point of using laboratory tests to identify practical features and reveal technical issues of each model, which remain hidden in simulation and theoretical phases. Due to electrical grid conditions, such as the voltage and frequency variations, the emulated profiles were different from the numerical curves. This is an important point from the economic aspect's standpoint, as these little differences between the emulated and numerical profiles can cause a huge variation in the final cost calculations, namely the monthly electricity costs.

\section{REFERENCES}

[1] Y. Mekonnen, L. Burton, A. Sarwat, and S. Bhansali, "IoT Sensor Network Approach for Smart Farming: An Application in Food, Energy and Water System," in 2018 IEEE Global Humanitarian Technology Conference (GHTC), 2018, pp. 1-5.

[2] FAO, "The Water-Energy-Food Nexus- A new Approach in Support of Food Security and Sustainable Agriculture," 2014. [Online]. Available: http://www.fao.org/3/a-b1496e.pdf. [Accessed: 06-Nov-2019].

[3] M. A. Jiménez-Bello, A. Royuela, J. Manzano, A. G. Prats, and F. Martínez-Alzamora, "Methodology to improve water and energy use by proper irrigation scheduling in pressurised networks," Agric. Water Manag., vol. 149, pp. 91-101, Feb. 2015.

[4] M. S. Mekala and P. Viswanathan, "A Survey: Smart agriculture IoT with cloud computing," in 2017 International conference on Microelectronic Devices, Circuits and Systems (ICMDCS), 2017, pp. $1-7$.

[5] W. Malik and F. Dechmi, "DSSAT modelling for best irrigation management practices assessment under Mediterranean conditions," Agric. Water Manag., vol. 216, pp. 27-43, May 2019.

[6] X. Dong, M. C. Vuran, and S. Irmak, "Autonomous precision agriculture through integration of wireless underground sensor networks with center pivot irrigation systems," Ad Hoc Networks, vol. 11, no. 7, pp. 1975-1987, Sep. 2013.

[7] I. A. Saeed et al., "Development of a Low-Cost Multi-Depth Real-Time Soil Moisture Sensor Using Time Division Multiplexing Approach," IEEE Access, vol. 7, pp. 19688-19697, 2019.

[8] O. Abrishambaf, P. Faria, Z. Vale, and J. M. Corchado, "Energy Scheduling Using Decision Trees and Emulation: Agriculture Irrigation with Run-of-the-River Hydroelectricity and a PV Case Study," Energies, vol. 12, no. 20, p. 3987, Oct. 2019.

[9] J. Zhang et al., "The water-food-energy nexus optimization approach to combat agricultural drought: a case study in the United States," Appl. Energy, vol. 227, pp. 449-464, Oct. 2018.

[10] L. Zhou, J. Yang, W. Wang, F. Liu, and Z. Liao, "Local Consumption of DG in Multiple Energy Forms for Facility Agriculture with TimeShifting Loads," in 2018 2nd IEEE Conference on Energy Internet and Energy System Integration (EI2), 2018, pp. 1-6.

[11] O. Abrishambaf, P. Faria, L. Gomes, and Z. Vale, "Agricultural irrigation scheduling for a crop management system considering water and energy use optimization," Energy Reports, vol. 6, pp. 133-139, Feb. 2020.

[12] O. Abrishambaf, P. Faria, and Z. Vale, "Energy Resource Scheduling in an Agriculture System Using a Decision Tree Approach," in 20th International Conference on Intelligent Systems Applications to Power Systems (ISAP), 2019.

[13] A. Ghasemi, "Coordination of pumped-storage unit and irrigation system with intermittent wind generation for intelligent energy management of an agricultural microgrid," Energy, vol. 142, pp. 1-13, Jan. 2018.

[14] FOA, "Chapter 2 - FAO Penman-Monteith equation." [Online]. Available: http://www.fao.org/3/X0490E/x0490e06.htm. [Accessed: 06-Nov-2019]. 